\title{
Control Strategy Based on Wavelet Transform and Neural Network for Hybrid Power System
}

\author{
Y. D. Song, ${ }^{1,2}$ Qian Cao, ${ }^{2}$ Xiaoqiang Du, ${ }^{2}$ and Hamid Reza Karimi ${ }^{3}$ \\ ${ }^{1}$ School of Automation, Chongqing University, Chongqing 400044, China \\ ${ }^{2}$ School of Energy Science and Engineering, University of Electronic Science and Technology of China, Chengdu 611731, China \\ ${ }^{3}$ Department of Engineering, Faculty of Engineering and Science, University of Agder, 4898 Grimstad, Norway
}

Correspondence should be addressed to Qian Cao; 403226080@qq.com

Received 31 July 2013; Accepted 26 September 2013

Academic Editor: Tao Zou

Copyright (C) 2013 Y. D. Song et al. This is an open access article distributed under the Creative Commons Attribution License, which permits unrestricted use, distribution, and reproduction in any medium, provided the original work is properly cited.

\begin{abstract}
This paper deals with an energy management of a hybrid power generation system. The proposed control strategy for the energy management is based on the combination of wavelet transform and neural network arithmetic. The hybrid system in this paper consists of an emulated wind turbine generator, PV panels, DC and AC loads, lithium ion battery, and super capacitor, which are all connected on a DC bus with unified DC voltage. The control strategy is responsible for compensating the difference between the generated power from the wind and solar generators and the demanded power by the loads. Wavelet transform decomposes the power difference into smoothed component and fast fluctuated component. In consideration of battery protection, the neural network is introduced to calculate the reference power of battery. Super capacitor (SC) is controlled to regulate the DC bus voltage. The model of the hybrid system is developed in detail under Matlab/Simulink software environment.
\end{abstract}

\section{Introduction}

Faced with shortage of oil, rising of the petroleum price and the increasing pollution of the environment, people all over the world are searching for solutions to energy crises. Since the end of the twentieth century, great attention has been paid to renewable energy sources [1]. Wind energy and solar energy are both sustainable and nonpolluting sources and they are potentially to be alternative sources over traditional energy [2]. Utilizing renewable energy sources like the sun and wind, hybrid renewable energy system is becoming popular in economic and environmental ways.

However, the power of wind generator and solar panels is fluctuant and discontinuous, so it is highly necessary to add storage system to a single energy or hybrid energy supply to smooth the electrical power. Researches are being studied all over the world to solve the energy management problem of a DC microgrid with hybrid power generators, especially with renewable energy power generators. Kalantar and Mousavi [3] studied the dynamic behavior of stand-alone hybrid power generation system with battery storage, using a supervisory controller based on programming to balance the energy within the system. Chen et al. [4] designed and implemented an energy management system (EMS) with fuzzy control for a DC microgrid system. Ko et al. [5] proposed a fuzzy controller and utilized sliding mode nonlinear control to keep a hybrid power system robust. Zhang et al. [6-8] investigated the problem of robust static output feedback (SOF) control and step tracking control problem for discrete-time nonlinear systems. Yin et al. [9-11] proposed a method of fault diagnosis scheme with parameters directly identified from the process data and compared the results of this data-driven method with process monitoring method.

Lithium ion batteries possess high energy density, relative high power density, long life span, and environmental friendliness and thus have been used in a wide range of areas [12]. Other types of batteries do not have the above advantages at the same time. For example, lead-acid batteries have much lower energy density than lithium ion batteries and often need to be in float charging state. The favorable characteristics 
of lithium ion battery are very beneficial for hybrid energy system to improve its energy capacity. Yet the transient power frequency and fluctuating output voltage of the generating system may pose great pressure on the battery, which may reduce its lifetime span and worsen its performance. Besides, the relatively low power density makes it difficult for battery alone to meet the rapid changing of power generated by the nonstable renewable energy. Therefore, another auxiliary storage unit, along with battery storage system, may improve the system performance in prolonging the life span of lithium ion battery and providing more smoothed power flow for the loads.

Recently, super capacitors are being researched for many good qualities, such as considerably higher power densities than those of batteries and tremendous higher energy density than that of regular capacitors [13]. The high power density of SC is suitable for smoothing and the difference between the rapid changing generated power and the load demands caused by the power fluctuation. Besides, since their operation does not employ a chemical reaction, SCs are much more robust than batteries, which provide a long cycle life that is at least 500 times more than that of standard batteries [14]. For the listed reasons above, we can come to the conclusion that battery system with super capacity as auxiliary storage unit is beneficial for a hybrid power system to provide high quality power and meet the loads demands. In Kamel's research, ultracapacitor based energy storage system is developed to smooth the output power of wind turbine and enhance MG's performance in islanding mode [15]. Erdinc added ultracapacitor to hybrid vehicular power system to improve the efficiency and dynamic response of a vehicular system [16].

Due to the different characteristics of the renewable energy and the storage system, an energy management strategy is proposed in this paper to reduce the difference between the generated power and the power demanded by loads. Wavelet transform is applied to decompose the different power into smoothed component and high fluctuation component. The two components are suitable for battery and SC to compensate, respectively, according to their different features. What is more, to prevent the battery from overcharge and deep discharge, neural network algorithm is employed after the wavelet transform. The battery is mainly in charge of compensating most of the difference between the generated power and the demanded power, while the SC is mainly responsible for stabilizing the voltage on the DC bus of the whole system, which indirectly compensates the rest of the power difference.

This paper describes a standalone hybrid renewable energy power generation system with hybrid storage system consisting of lithium ion battery and SC, using a wavelet neural network based control strategy. The contents are organized as follows. Section 2 illustrates the modeling of the system components, respectively, including wind power generator, PV generator, lithium ion battery, and SC. Section 3 elaborates the wavelet neural network control strategy for the energy management system. The test results and discussion are given in Section 4.

\section{System Description and Components Modeling}

The proposed hybrid system consists of a wind turbine, a PV panel and a lithium ion battery, and SC based energy storage system. All the components are connected to a voltage uniformed DC bus with converters as is shown in Figure 1.

2.1. Wind Turbine Modeling. We assume a wind turbine driven by a permanent synchronous generator (PMSG) in this study. The rated output power and rated wind speed of the wind turbine are $600 \mathrm{~W}$ and $13 \mathrm{~m} / \mathrm{s}$. The starting wind speed is $3 \mathrm{~m} / \mathrm{s}$, and the maximum wind speed is $18 \mathrm{~m} / \mathrm{s}$. The maximum output power is $800 \mathrm{~W}$. The model of wind turbine is built in Matlab/Simulink software. According to the aerodynamic theory, the output power of the wind turbine can be expressed as

$$
P_{m}=0.5 \rho \pi R^{2} V_{w}^{2} C_{p}(\lambda, \beta),
$$

where $P_{m}$ is the output power extracted from wind turbine generator. $\rho, R$, and $V_{w}$ represent the air density, the blade radium, and the wind speed, respectively. $C_{p}$ is the power coefficient, which can be expressed as a function of tip speed ratio $\lambda$ and the blade pitch angle $\beta$ as follows:

$$
C_{p}(\lambda, \beta)=0.73\left(\frac{151}{\lambda}-0.58 \beta-0.002 \beta^{2.14}-13.2\right) e^{-18.4 / \lambda} .
$$

in which

$$
\lambda=\frac{1}{\left(1 /(\lambda-0.02 \beta)-0.003 /\left(\beta^{3}+1\right)\right)} .
$$

A $13 \mathrm{~m} / \mathrm{s}$ turbulent wind is generated from Bladed/FAST software and plotted in Matlab, shown in Figure 2. The output power of the wind turbine under MPPT control is shown in Figure 3.

2.2. PV Array Modeling. PV array is built by several PV cells connecting in series and parallel. The short-circuit current of each PV cell is calculated by the following equation:

$$
I_{\mathrm{sc}}=I_{\mathrm{sc0}}\left(\frac{G}{G_{0}}\right)^{\alpha},
$$

where $I_{\mathrm{sc}}$ and $I_{\mathrm{sc} 0}$ represent the short-circuit currents under standard and normal solar radiation $G$ and $G_{0}$ and $\alpha$ reflects all the nonlinear effects.

The open-circuit voltage of the PV cell is

$$
V_{\mathrm{oc}}=\frac{V_{\mathrm{oc} 0}}{1+\beta \ln \left(G / G_{0}\right)} \cdot\left(\frac{T_{0}}{T}\right)^{\gamma},
$$

where $V_{\mathrm{oc}}$ and $V_{\mathrm{oc} 0}$ represent the open-circuit voltage under standard and normal solar radiation $G$ and $G_{0}$ and $T$ is the temperature of PV cell. $\beta$ is a specific technology-related coefficient of PV cell and $\gamma$ reflects the nonlinear effects of temperature. 


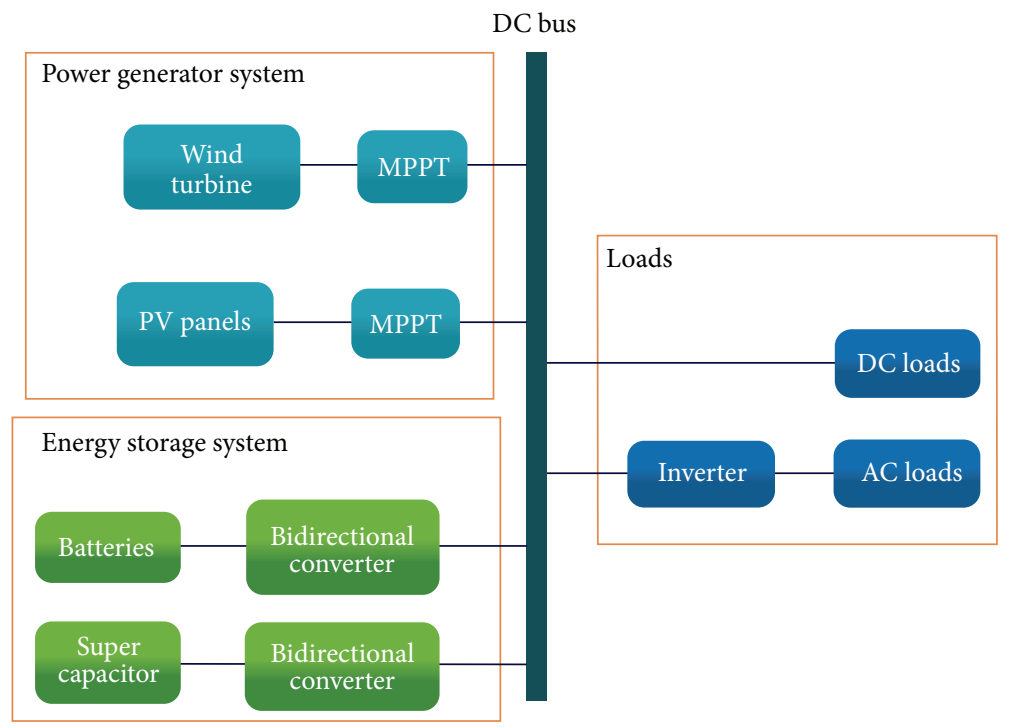

FIGURE 1: Hybrid power system structure.

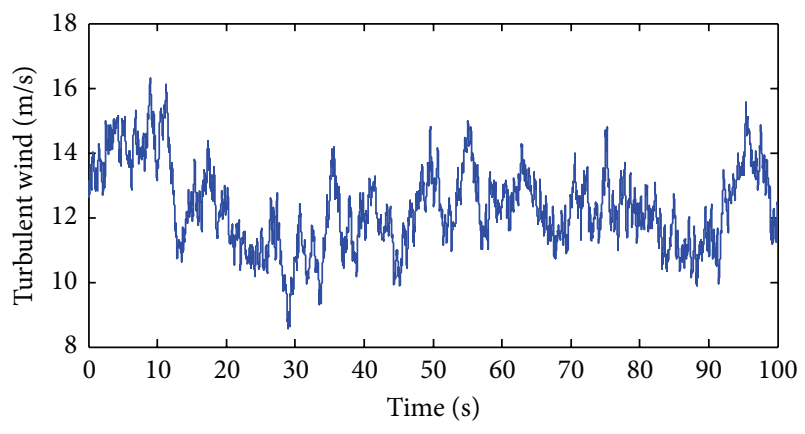

Figure 2: Turbulent wind of $13 \mathrm{~m} / \mathrm{s}$ from Bladed/FAST software.

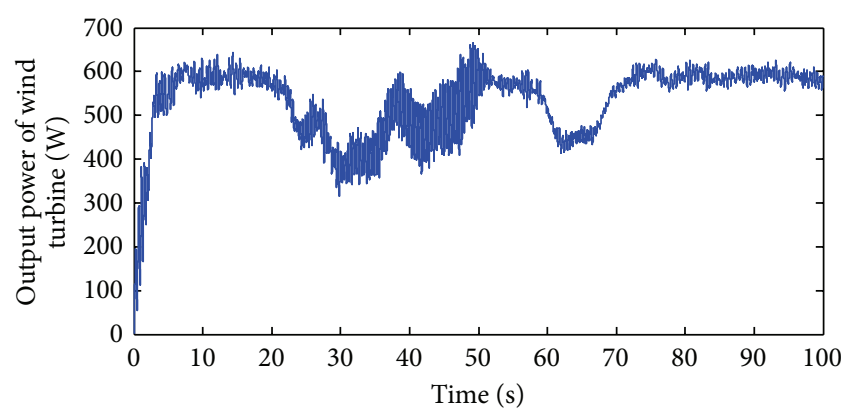

FIgURE 3: The output power of the $600 \mathrm{~W}$ wind turbine with turbulent wind of $13 \mathrm{~m} / \mathrm{s}$.

The maximum output power from the PV array with $N_{s}$ PV cells connected in series and $N_{p}$ series groups in parallel can be written as

$$
\begin{aligned}
P_{\max }= & N_{p} \cdot N_{s} \cdot \frac{V_{\mathrm{oc} 0} / n k T q-\ln \left(V_{\mathrm{oc}} / n k T q+0.72\right)}{1+V_{\mathrm{oc} 0} / n k T q} \\
& \cdot\left(1-\frac{R_{s}}{V_{\mathrm{oc}} / I_{\mathrm{sc}}}\right) \cdot V_{\mathrm{oc}} \cdot I_{\mathrm{sc} .}
\end{aligned}
$$

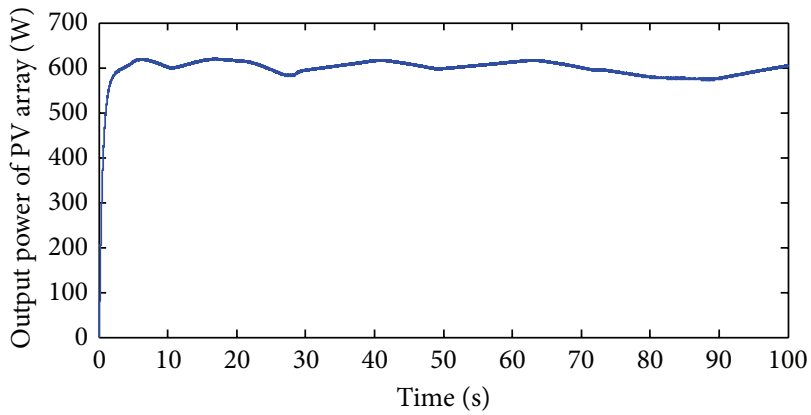

FIgURE 4: The maximum output power of PV array.

The maximum output power from PV array is shown in Figure 4.

Since the power of wind turbine and PV array are both obtained, the total generated power can be calculated by adding them together. In addition, we assume that the load demand is constant $1 \mathrm{~kW}$. So the power difference between the generated power and the demanded power by the loads $\Delta P$ is

$$
\Delta P=P_{\mathrm{WP}}+P_{\mathrm{PV}}-P_{L}
$$

in which $P_{\mathrm{WP}}, P_{\mathrm{PV}}$, and $P_{L}$ are wind turbine output power, $\mathrm{PV}$ array output power, and load demanded power, respectively. Variation of $\Delta P$ over time in this paper is shown in Figure 5.

2.3. Energy Storage System. As is mentioned before, the power generated from the renewable energy includes many sharp and transient variations, which makes it hard to meet the relatively smoothed load power demand. Therefore, it is necessary to compensate the gap between the generated power and the demanded power. In this scheme, the power that generated by the renewable energies and power that is demanded by the load are coordinated by the energy 


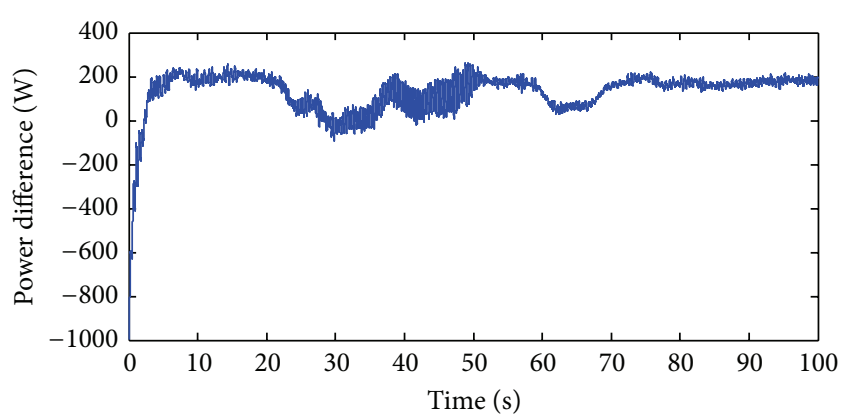

FIGURE 5: Variation of $\Delta P$.

storage system which is composed of lithium ion battery bank and super capacitor (SC). Battery has high energy density, whereas it has relatively slow charging and discharging speed. On the other hand, super capacitor has the advantage of quick charge, large power density, and long cycle life [17]. SC in a hybrid energy storage system can quickly respond to the power smoothing instructions and better complete power smoothing tasks [18]. Based on the above characteristics, a modified coordinated control strategy, by which the total generated power can be smoothed and the loads demand can be met as well, is proposed and elaborated in the following chapters.

(1) Lithium Ion Battery Bank Modeling. The battery module from the Matlab/Simulation software is adopted in this paper. This model allows users to apply parameters based on battery type and nominal values. The battery bank in this paper consists of four batteries connected in parallel, each of which is of $24 \mathrm{~V}$ nominal voltage and $5 \mathrm{Ah}$ rated capacity. That makes the total capacity of the battery bank $20 \mathrm{Ah}$. The parameters of the lithium ion battery are listed in Table 1.

(2) Super Capacitor Modeling. A classical equivalent model for SC is shown in Figure 6, which consists of a capacitance $(C)$, an equivalent series resistance $\left(R_{S}\right)$ representing the charging and discharging resistance, and an equivalent parallel resistance $\left(R_{P}\right)$ representing the self-discharging losses [19]. Instead of using the common RC equivalent circuit, a modified electrical equivalent circuit for super capacity, as is shown in Figure 7, is applied in this paper. The RC branch in the modified equivalent circuit composed of $R_{S}$ and $C_{1}$ is called the "fast branch" and is used to represent the immediate behavior of the SC in the time range of seconds. The RC branch comprising $R_{2}$ and $C_{2}$ is called the "slow branch" and this RC branch presents the internal energy distribution at the end of charge or discharge [20].

\section{System Control Strategy}

In this section, a wavelet transform and neural network based control strategy is introduced to manage the system energy. The advantage of wavelet analysis, as opposed to conventional techniques, is that wavelet transform decomposes a signal into a series of short duration waves or local basis functions (wavelets) on the time axis which allows the analysis of

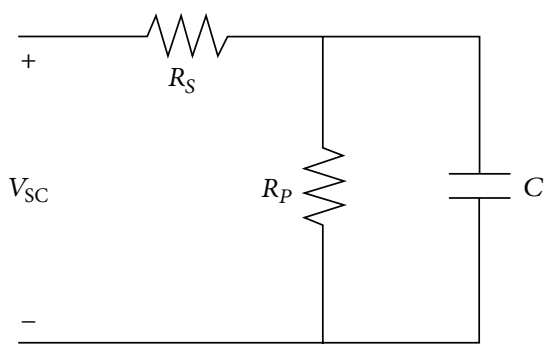

FIGURE 6: Classical equivalent model for SC.

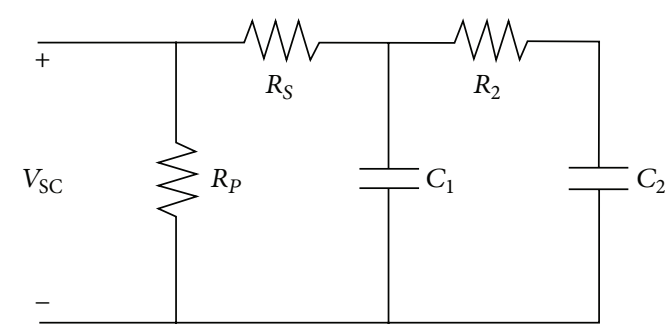

Figure 7: Modified equivalent model for SC.

TABLE 1: Lithium ion battery bank parameters.

\begin{tabular}{lc}
\hline Parameter & Value \\
\hline Nominal voltage & $24 \mathrm{~V}$ \\
Rated capacity & $20 \mathrm{Ah}(4 * 5 \mathrm{Ah})$ \\
Maximum capacity & $20 \mathrm{Ah}(4 * 5 \mathrm{Ah})$ \\
Fully charged voltage & $27.9357 \mathrm{~V}$ \\
Nominal discharge current & $8.6957 \mathrm{~A}$ \\
Internal resistance & $12 \mathrm{~m} \Omega(48 / 4 \mathrm{~m} \Omega)$ \\
\hline
\end{tabular}

local phenomena in signals consisting of many transients [21]. In this case, we apply a three-level Haar wavelet. The original signal for wavelet transform is $\Delta P$, the difference between the total generated power $P_{\mathrm{WP}}+P_{\mathrm{PV}}$ and the load demand $P_{L}$. Then $\Delta P$ is decomposed into approximation component $\Delta P_{a}$ and detailed component $\Delta P_{d}$ by wavelet transform. According to the different respond speed and power density characteristics of the two types of storage devices mentioned above, the majority of $\Delta P_{a}$, which is the smoothed component of the total difference, is convenient to be met by battery, while the detailed part $\Delta P_{d}$, which contains a lot of high frequency components, is suitable for super capacity to compensate. The decomposition is illustrated in Figure 8.

However, if we assign $\Delta P_{a}$ to be the exact reference power of battery directly, it is highly possible that the batteries would reach out their acceptable SOC limit, which would cause some certain damages to the batteries and reduce its lifetime. Therefore, neural network is introduced to maintain the SOC of batteries within a reasonable range, so that they can function in good condition. In this paper, adaptive linear (ADALINE) neural network is applied to obtain the reference power of battery storage system. Figure 9 shows the general neural network model. $p_{1}, p_{2}$ are the inputs of network controller; $W_{1}$ and $W_{2}$ are the corresponding 

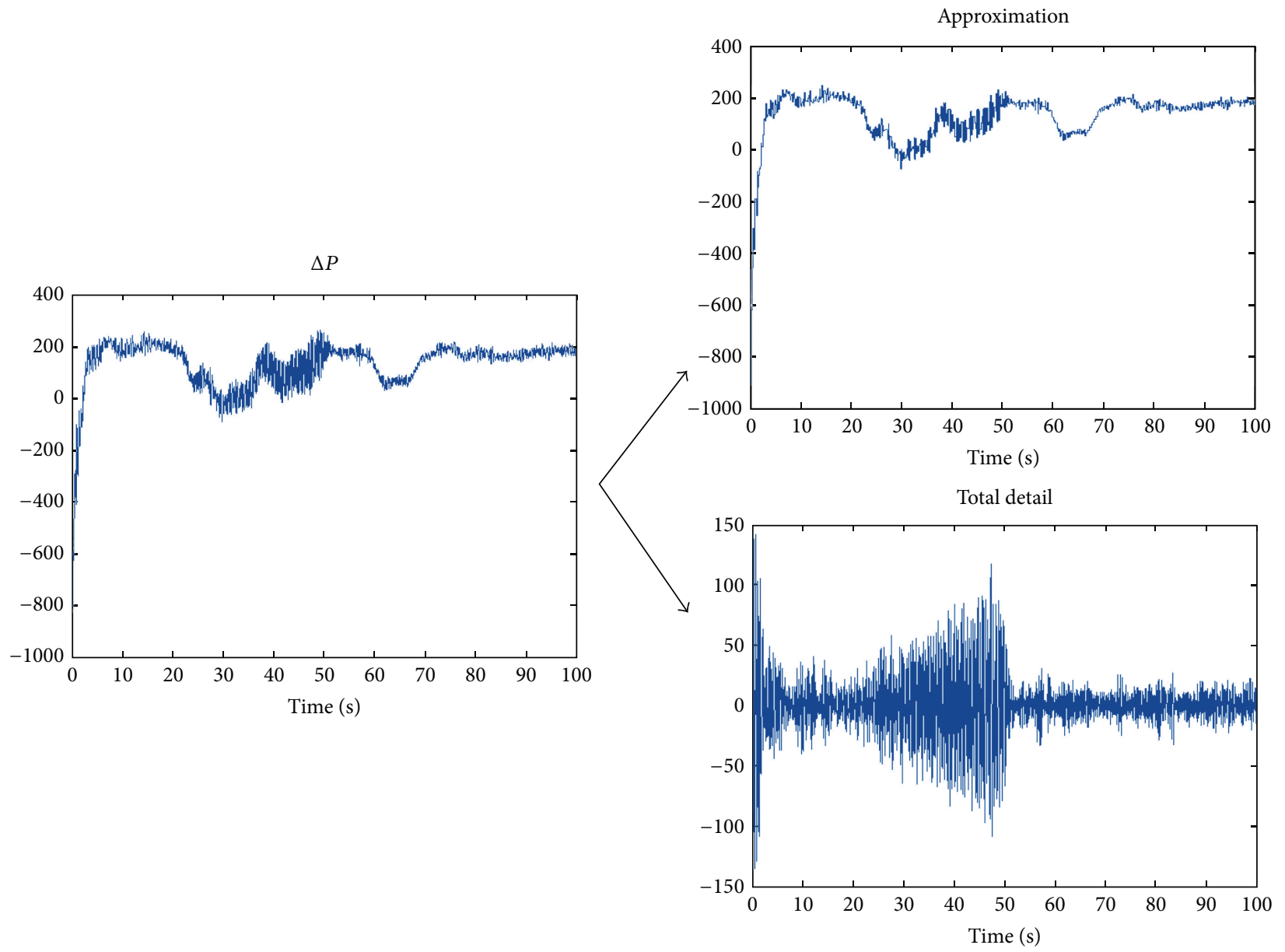

Figure 8: Decomposition of power difference $\Delta P$ using Haar wavelet transform.

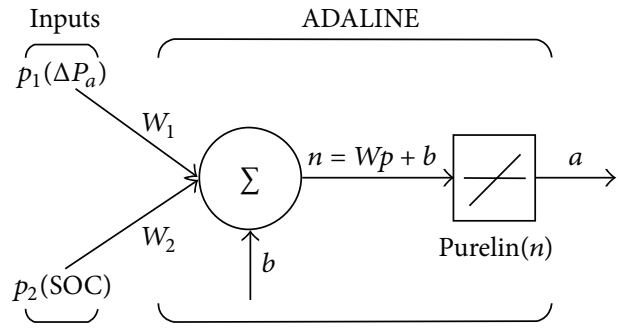

FIGURE 9: Model of a simple ADALINE neural network.

weight of the two inputs parameters; $b$ represents bias and $n$ represents the net input; $a$ is the output of the network controller. In this case, the inputs of the neural network are $\Delta P_{a}$-the approximation component of the total different $\Delta P$ after wavelet transformation, and the SOC of the battery. By utilizing the input parameters, the neural network controller determines the reference power for battery. The first half data of $\Delta P_{a}$ is used to train the perception. The target value of battery SOC is set as 0.7. If the SOC of battery is around the desired value, then the reference power for battery is $\Delta P_{a}$. However, if the SOC is more/less than the desired value, the reference power is more/less than $\Delta P_{a}$, in order to decrease/increase the SOC to the target. This way, the battery would be protected from being overcharged or deep discharged.

The whole configuration of the wavelet neural network controller is illustrated in Figure 10. This scheme is composed of a battery bank and a super capacity using two bidirectional DC/DC converters, respectively, for power tracking and voltage regulation. The reference power for the battery is obtained by the wavelet neural network elaborated above. A PI controller is then followed to track the battery's actual power and the system response can be achieved by generating PWM switching signals to DC/DC converters. Besides, the DC bus voltage is regulated by controlling the bidirectional DC/DC converter coupled with SC.

\section{Simulation Results}

We set the learning step of the neural network 0.008 and the mean square error 0.005 . The network is trained using the first half of operation data according to the principles mentioned in Section 3. The output power of battery is demonstrated in Figure 11. It is obvious that the variation of battery output power is similar to $\Delta P_{a}$ the approximation component of power difference after wavelet transform. As 


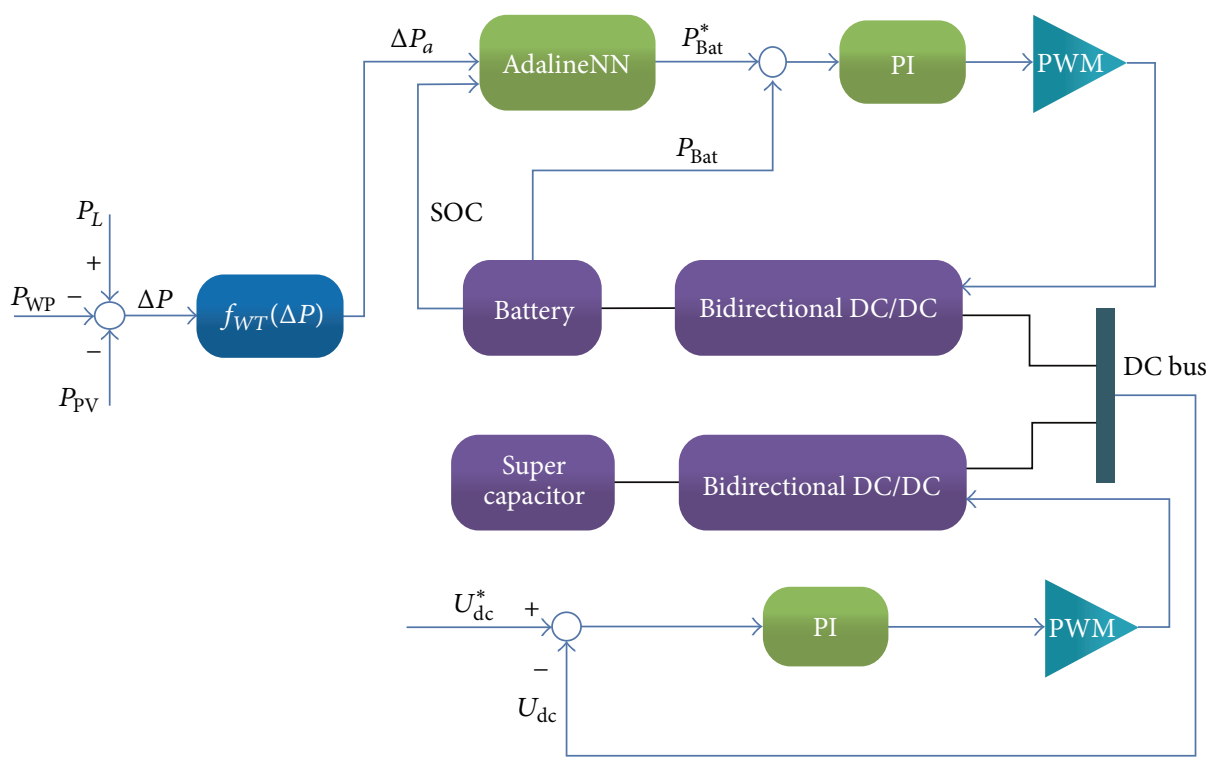

FIGURE 10: Wavelet and neural network controller based energy management system.

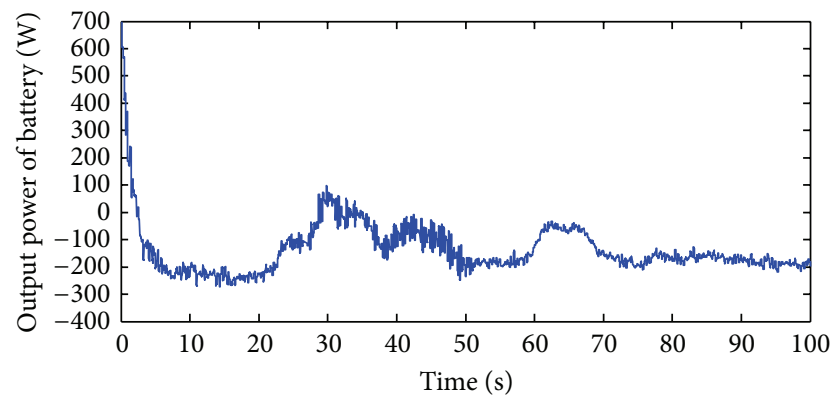

FIGURE 11: The output power of the lithium ion battery.

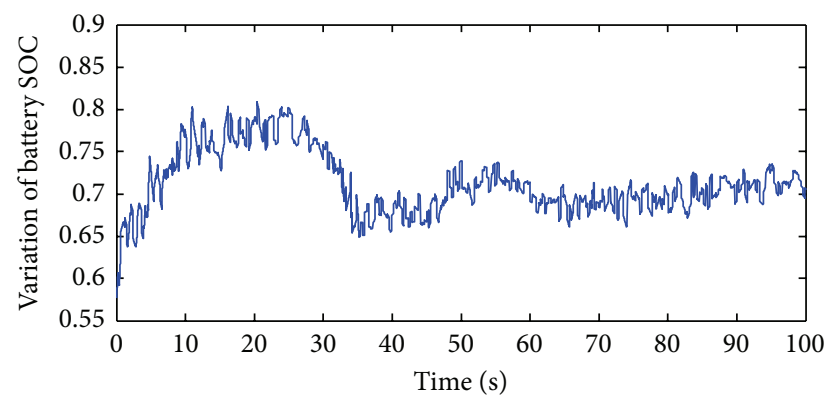

FIgURE 12: The variation of SOC of the lithium ion battery.

we can see, the changes of the battery power possess less sharp transition part than the original power difference $\Delta P$ shown in Figure 5. This protects the battery from being damaged by extremely fast charging and discharging operation.

The variation of battery SOC is demonstrated in Figure 12. The SOC is sustained near 0.7 as we designed in the neural network controller.

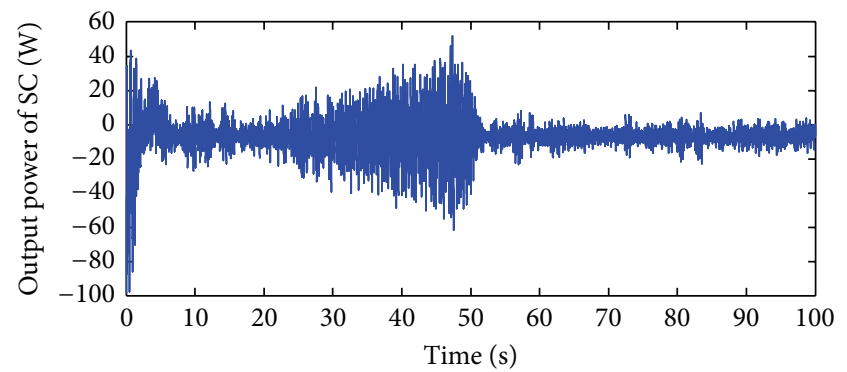

FIGURE 13: The output power of the super capacitor.

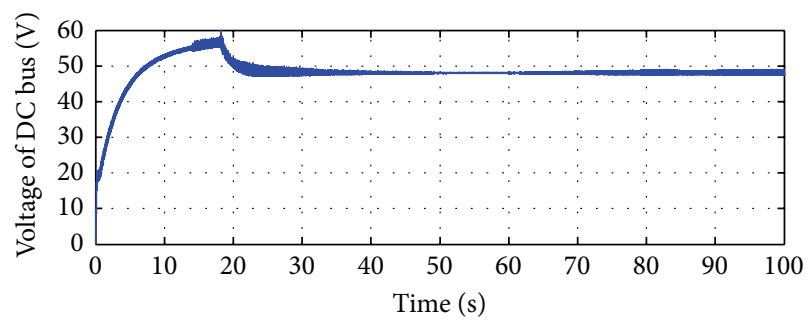

FIGURE 14: The variation of DC bus voltage.

Figure 13 shows the output power of super capacitor, which resembles the detailed part of the power difference after wavelet transform.

The variation of the DC bus voltage is shown in Figure 14. The voltage is sustained within a reasonable limit by generating proper PWM signals to super capacitor, which is important for the loads connected on the DC bus. As is illustrated in the figure, the voltage of the DC bus maintained at the point of $48 \mathrm{~V}$ after a short fluctuation at the beginning.

The simulation results show that the proposed method effectively keeps the microgrid operating under stable state 
with power fluctuation injected in it by making full use of two different storage units. The salient features of the proposed method include: (1) effective in dealing with modeling uncertainties; (2) structurally simple and computationally inexpensive; and (3) the design parameters can be readily determined, which makes it much easier than tuning conventional PID controller.

\section{Conclusion}

This paper proposes a wavelet transform and neural network based energy management system for hybrid power system. The hybrid power system consists of wind power subsystem, solar power subsystem, and an energy storage system. The wind turbine and PV array are all controlled under MPPT to obtain maximum electrical power. The energy storage system includes lithium ion battery bank and super capacitor which are controlled under the proposed energy management system. In the proposed control strategy, wavelet is in charge of decomposing and then reconfiguring the power difference between generated power and consumed power by loads. The approximation part is compensated by battery bank. In consideration of sustaining its SOC within an acceptable limit, neural network controller is introduced. Then the voltage of system DC bus is maintained by rapidly charging and discharging the super capacitor.

The simulation results demonstrate that the proposed strategy is capable of compensating the variation power difference caused by the renewable energy and the loads, as well as maintaining the DC voltage stable. Furthermore, the SOC of batteries is within the recommended range, thus protecting them from being damaged by overcharge and deep discharge. Since the modeling of the system is complex and difficult, future work will be more focused on data-driven controller design for microgrid.

\section{Acknowledgments}

This work is supported in part by the National Basic Research Program of China (973 Program no. 2012CB215200) and in part by the National Natural Science Foundation of China (no. 51205046).

\section{References}

[1] R. Pecen and A. Nayir, "Design and implementation of a $12 \mathrm{~kW}$ wind-solar distributed power and instrumentation system as an educational testbed for Electrical Engineering Technology students," in Proceedings of the International Symposium on Modern Electric Power Systems (MEPS '10), pp. 1-6, September 2010.

[2] Y. Xie, J. Sun, C. Mi, and J. S. Freudenberg, "Analysis and modeling of a DC hybrid power system testbed for power management strategy development," in Proceedings of the 5th IEEE Vehicle Power and Propulsion Conference (VPPC '09), pp. 926-933, September 2009.

[3] M. Kalantar and S. M. Mousavi, "Dynamic behavior of a stand-alone hybrid power generation system of wind turbine, microturbine, solar array and battery storage," Applied Energy, vol. 87, no. 10, pp. 3051-3064, 2010.

[4] Y. K. Chen, Y. C. Wu, C. C. Song, and Y. S. Chen, "Design and implementation of energy management system with fuzzy control for DC microgrid systems," IEEE Transactions on Power Electronics, vol. 28, no. 4, pp. 1563-1570, 2013.

[5] H.-S. Ko, G.-G. Yoon, W.-P. Hong, and J. Jatskevich, "Control of hybrid wind power generation system with dump load using advanced fuzzy-robust controller," in Proceedings of the International Conference on Electrical Machines and Systems (ICEMS '07), pp. 219-226, October 2007.

[6] H. Zhang, Y. Shi, and A. Saadat Mehr, "Robust static output feedback control and remote PID design for networked motor systems," IEEE Transactions on Industrial Electronics, vol. 58, no. 12, pp. 5396-5405, 2011.

[7] H. Zhang, Y. Shi, and A. Saadat Mehr, "Robust non-fragile dynamic vibration absorbers with uncertain factors," Journal of Sound and Vibration, vol. 330, no. 4, pp. 559-566, 2011.

[8] H. Zhang, Y. Shi, and M. Liu, " $H_{\infty}$ step tracking control for networked discrete-time nonlinear systems with integral and predictive actions," IEEE Transactions on Industrial Informatics, vol. 9, no. 1, pp. 337-345, 2013.

[9] S. Yin, S. X. Ding, A. Haghani, H. Hao, and P. Zhang, "A comparison study of basic data-driven fault diagnosis and process monitoring methods on the benchmark Tennessee Eastman process," Journal of Process Control, vol. 22, no. 9, pp. 1567-1581, 2012.

[10] S. Yin, X. Yang, and H. R. Karimi, "Data-driven adaptive observer for fault diagnosis," Mathematical Problems in Engineering, vol. 2012, Article ID 832836, 21 pages, 2012.

[11] S. Yin, S. X. Ding, A. H. Abandan Sari, and H. Hao, "Data-driven monitoring for stochastic systems and its application on batch process," International Journal of Systems Science, vol. 44, no. 7, pp. 1366-1376, 2013.

[12] L. Lu, X. Han, J. Li, J. Hua, and M. Ouyang, "A review on the key issues for lithium-ion battery management in electric vehicles," Journal of Power Sources, vol. 226, pp. 272-288, 2013.

[13] M. Akbari, S. M. M. Tafreshi, and M. A. Golkar, "Voltage control of a hybrid ac/dc microgrid in stand-alone operation mode," in Proceedings of the IEEE PES International Conference on Innovative Smart Grid Technologies-India (ISGT India '11), pp. 363-367, December 2011.

[14] Y. Ates, O. Erdinc, M. Uzunoglu, and B. Vural, "Energy management of an FC/UC hybrid vehicular power system using a combined neural network-wavelet transform based strategy," International Journal of Hydrogen Energy, vol. 35, no. 2, pp. 774783, 2010.

[15] R. M. Kamel, A. Chaouachi, and K. Nagasaka, "Wind power smoothing using fuzzy logic pitch controller and energy capacitor system for improvement Micro-Grid performance in islanding mode," Energy, vol. 35, no. 5, pp. 2119-2129, 2010.

[16] O. Erdinc, B. Vural, M. Uzunoglu, and Y. Ates, "Modeling and analysis of an FC/UC hybrid vehicular power system using a wavelet-fuzzy logic based load sharing and control algorithm," International Journal of Hydrogen Energy, vol. 34, no. 12, pp. 5223-5233, 2009.

[17] R. Lu, C. Zhu, L. Tian, and Q. Wang, "Super-capacitor stacks management system with dynamic equalization techniques," IEEE Transactions on Magnetics, vol. 43, no. 1, pp. 254-258, 2007.

[18] X. Han, F. Chen, X. Cui, Y. Li, and X. Li, "A power smoothing control strategy and optimized allocation of battery capacity 
based on hybrid storage energy technology," Energies, vol. 5, no. 5, pp. 1593-1612, 2012.

[19] M. Uzunoglu, O. C. Onar, and M. S. Alam, "Modeling, control and simulation of a PV/FC/UC based hybrid power generation system for stand-alone applications," Renewable Energy, vol. 34, no. 3, pp. 509-520, 2009.

[20] O. Erdinc, B. Vural, M. Uzunoglu, and Y. Ates, "Modeling and analysis of an FC/UC hybrid vehicular power system using a wavelet-fuzzy logic based load sharing and control algorithm," International Journal of Hydrogen Energy, vol. 34, no. 12, pp. 5223-5233, 2009.

[21] S. P. Valsan and K. S. Swarup, "Wavelet based transformer protection using high frequency power directional signals," Electric Power Systems Research, vol. 78, no. 4, pp. 547-558, 2008. 


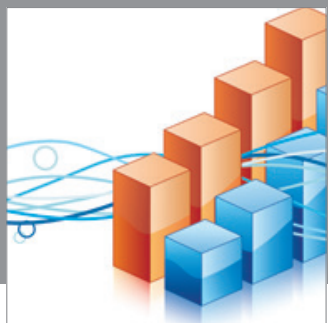

Advances in

Operations Research

mansans

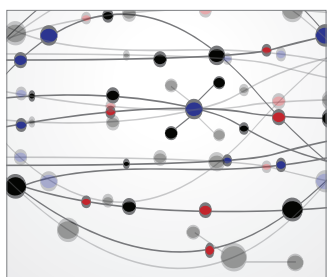

The Scientific World Journal
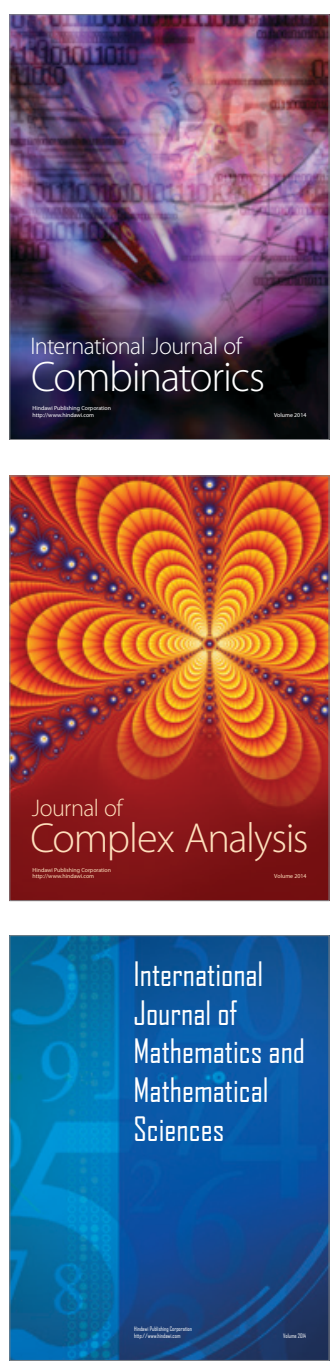
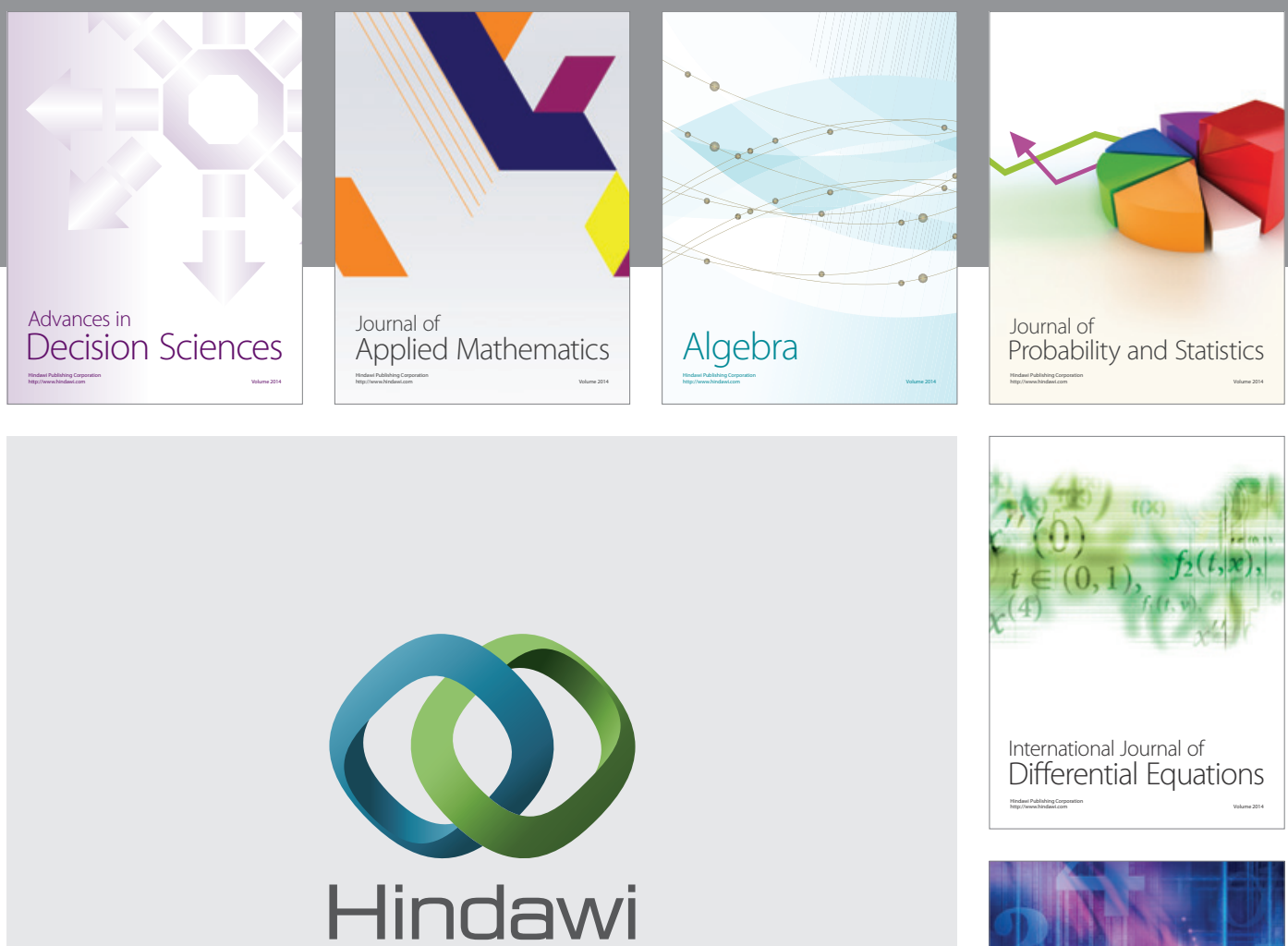

Submit your manuscripts at http://www.hindawi.com
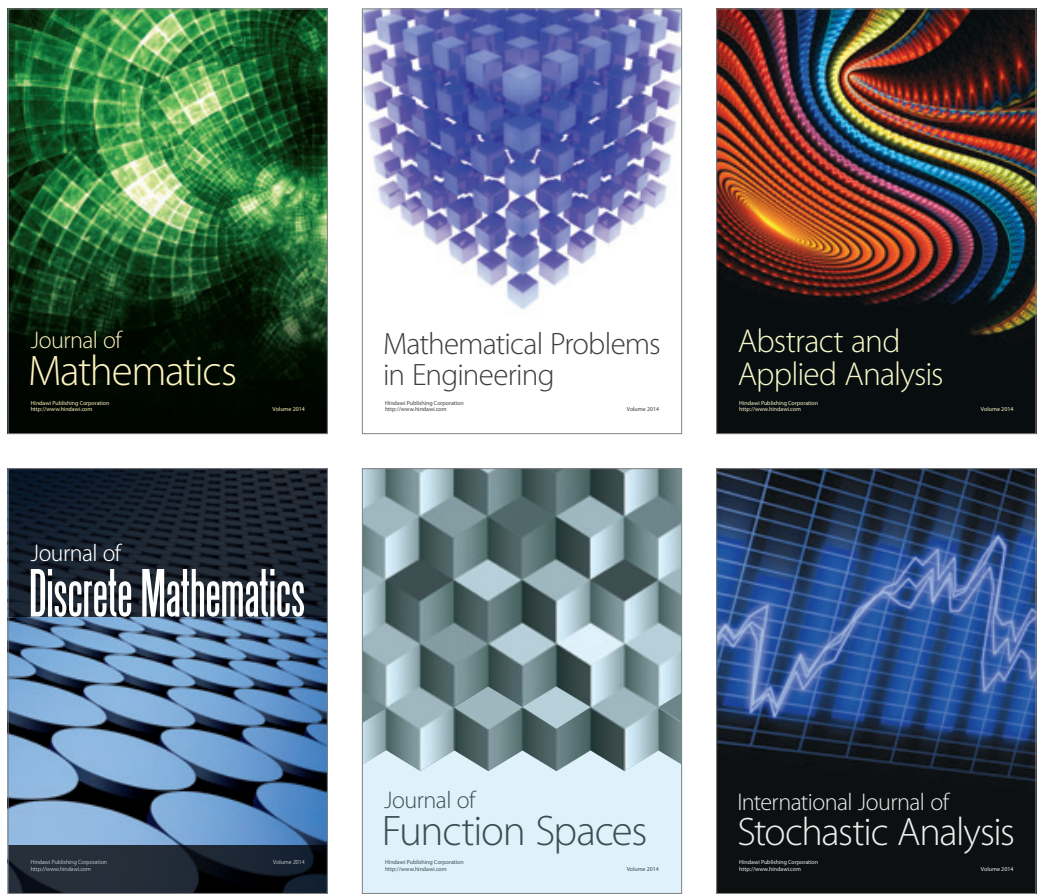

Journal of

Function Spaces

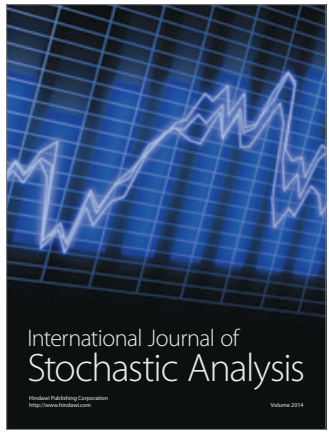

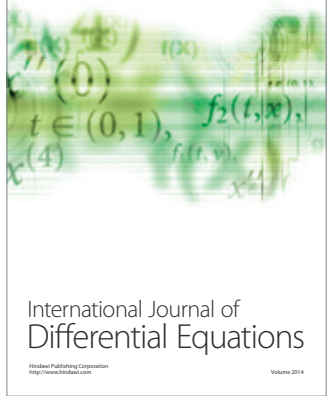
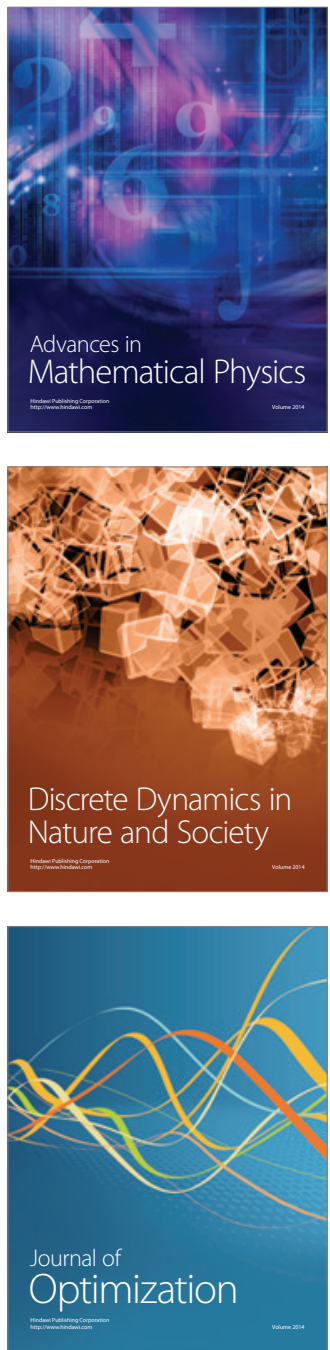